\title{
HIDROGENAÇÃO ELETROCATALÍTICA DE SUBSTRATOS ORGÂNICOS UTILIZANDO ELETRODOS MODIFICADOS POLIMÉRICOS CONTENDO PARTÍCULAS DE Ni/Pd E Ni/Pt
}

Fabiana L. S. Purgato e José R. Romero*

Departamento de Química, Faculdade de Filosofia Ciências e Letras de Ribeirão Preto, Universidade de São Paulo, Av. Bandeirantes, 3400, 14040-910 Ribeirão Preto - SP, Brasil

Luisa M. Abrantes

Departamento de Química e Bioquímica, Faculdade de Ciências, Universidade de Lisboa, 1294 Lisboa Codex, Portugal

Recebido em 25/8/08; aceito em 2/12/08; publicao na web em 11/5/09

\begin{abstract}
ELECTROCATALYTIC HYDROGENATION OF ORGANIC SUBSTRATES ON POLYMER MODIFIED ELECTRODES EMBEDDING Ni/Pd AND Ni/Pt PARTICLES. Novel modified electrodes bearing dispersed Pd and Pt particles have been prepared from poly (allyl ether of the $p$-benzenesulfonic acid) films with incorporated nickel particles making use of galvanic displacement reactions. The SEM analysis of the new modified electrodes revealed efficient deposition of Pd but weak up-take of Pt. Electrocatalytic hydrogenation of several classes of organic substrates were carried out using the MEs Ni, Ni/Pd and Ni/Pt. The Ni/Pd ME showed to be the best of them for the hydrogenation of double, triple and carbonyl bonds. The complete hydrogenation of the aromatic rings for the well-adsorbed substrates acetophenone and benzophenone is noteworthy.
\end{abstract}

Keywords: modified electrode; palladium and platinum particles; complete aromatic hydrogenation.

\section{INTRODUÇÃO}

A hidrogenação eletrocatalítica (HEC) $)^{1}$ e a catalítica ${ }^{2-6}$ envolvem a transferência de hidrogênio para moléculas orgânicas insaturadas quando ambas as espécies são adsorvidas na superfície de metais de transição, como níquel, paládio ou platina. Na hidrogenação catalítica clássica, o substrato e o hidrogênio usualmente requerem altas pressões e temperatura ${ }^{7}$ para serem adsorvidos e reagirem, enquanto que a eletrocatalítica requer temperatura ambiente e pressão atmosférica, já que os átomos de hidrogênio são gerados a baixos potenciais aplicados ao eletrodo a partir de prótons presentes na solução ácida.

É conhecido que a eficiência da $\mathrm{HEC}^{8-11}$ é determinada pela relativa habilidade dos substratos orgânicos adsorverem na superfície do eletrodo metálico, habilidade esta que depende de vários fatores como natureza do metal, potencial aplicado, $\mathrm{pH}$ e natureza do solvente.

Durante a última década ocorreu um grande desenvolvimento dos eletrodos modificados (EMs) que provêm sistemas com propriedades particulares no que concerne à reatividade e seletividade, com grande aplicação na catálise inorgânica ${ }^{12}$ e orgânica, como a hidrogenação de diferentes classes de substratos orgânicos. ${ }^{13-16}$

Filmes poliméricos têm sido usados largamente na preparação dos EMs. EM química e fisicamente estável pode ser preparado com o filme poli (éter alílico do ác. $p$-benzenossulfônico). ${ }^{17-23} \mathrm{~A}$ formação do filme polimérico resulta da eletrooxidação do ácido éter alilbenzeno $p$ sulfônico, através da formação de um cátion radical estabilizado pelo anel aromático que inicia uma reação em cadeia, originando o polímero. ${ }^{24} \mathrm{As}$ possibilidades de funcionalização do anel aromático na posição para são muito grandes, o que permite construir vários tipos de EMs ${ }^{18-23} \mathrm{O}$ grupo aniônico sulfonato pode ser usado para a incorporação de íons metálicos (como $\mathrm{NiSO}_{4}, \mathrm{PtCl}_{4}$ ou $\mathrm{PdCl}_{4}$ ) por troca iônica e a subseqüente eletrorredução do íon produz micro/nano partículas dispersas no filme. Assim, estudaram-se as HEC em vários materiais eletródicos e observou-se um bom comportamento químico dado pelos metais incorporados. ${ }^{18-23}$

No presente trabalho, as propriedades do poli (éter alílico do ác. $p$-benzenossulfônico) foram exploradas para incorporar níquel, que

*e-mail: jrromero@ffclrp.usp.br foi usado para promover reações de deslocamento galvânico ${ }^{25,26} \mathrm{a}$ fim de se obter dispersões de paládio ou platina no filme polimérico. Estes novos EMs foram caracterizados e usados na HEC de diferentes classes de substratos orgânicos.

\section{PARTE EXPERIMENTAL}

\section{Reagentes e equipamentos}

Os reagentes comerciais foram purificados quando necessário. As soluções foram preparadas com água deionizada.

A preparação do éter alílico do ác. p-benzenossulfônico está descrita na literatura, ${ }^{17}$ bem como sua polimerização para produzir filmes que revestiram eletrodos de bastão de grafite. ${ }^{27}$

Os experimentos em voltametria cíclica foram realizados numa cela cilíndrica convencional de um compartimento $(80 \mathrm{~mL})$ usando 4 bastões de grafite $(0,7 \times 4,5 \mathrm{~cm} \text { cada })^{27}$ presos num suporte de aço como um eletrodo de trabalho $\left(40 \mathrm{~cm}^{2}\right.$ de superfície recoberta com o filme), eletrodo de $\mathrm{Ag} / \mathrm{AgCl}$ como referência e fio de platina como eletrodo auxiliar. Foi empregado um potenciostato/galvanostato da PAR modelo 273A conectado a um programa Electrochemical Analysis Model 270.

Os bastões de grafite recobertos pelo filme poli (éter alílico do ác. p-benzenossulfônico) foram inicialmente mergulhados em uma solução de $\mathrm{NiSO}_{4} 0,5 \mathrm{~mol} \mathrm{~L}^{-1}$ durante $2 \mathrm{~h}$ para a troca do $\mathrm{H}^{+}$pelo $\mathrm{Ni}^{2+}$. Estes eletrodos foram lavados com água e transferidos para uma cela eletrolítica convencional contendo $\mathrm{KCl} 0,1 \mathrm{~mol} \mathrm{~L}^{-1}$ para a redução eletroquímica do $\mathrm{Ni}^{2+}$ a Ni, através de seis varreduras no intervalo de 0,0 a $-1,0 \mathrm{~V}$ versus $\mathrm{Ag} / \mathrm{ACl}$, com velocidade de varredura de 10 $\mathrm{mV} \mathrm{s}^{-1}$. Estes bastões de grafite assim preparados foram mergulhados por $5 \mathrm{~h}$ numa solução de $0,1 \mathrm{~g}$ de $\mathrm{PdCl}_{4}$ em $\mathrm{HCl}$ conc. sob vigorosa agitação. O mesmo procedimento foi utilizado para promover a troca $\mathrm{Ni} / \mathrm{Pt}$ utilizando-se uma solução de $\mathrm{PtCl}_{4}$. Assim foram preparados os EM's de Ni/Pd e Ni/Pt.

Os bastões de grafite podem ser recuperados para uso posterior removendo-se o filme e os metais incorporados polindo-os com o abrasivo PK-4 da Bioanalytical System Inc. (BAS). 
A morfologia da superfície, a microestrutura e composição elementar dos filmes depositados foram analisadas por microscopia eletrônica de varredura (MEV) ${ }^{28}$ e espectrometria de energia dispersiva de raios-X (EDX) num Leica-Zeiss LEO 440 modelo SEM acoplado a um analisador Oxford modelo 7060, utilizando uma pastilha de grafite com $3 \times 6,38 \mathrm{~mm}$.

Os espectros de ressonância nuclear magnética protônica $\left({ }^{1} \mathrm{H}\right.$ RMN) foram obtidos num espectrofotômetro Brucker AC-400 (400 $\mathrm{MHz}$ ). O espectro de absorção no infravermelho foi obtido num espectrofotômetro Perkin-Elmer 1600 series FTIR usando KBr. Cromatografias gás-líquido (c.g.l.) foram realizadas num cromatógrafo a gás Intralab 4290 contendo uma coluna OV 17. Um detector de chama foi utilizado.

\section{Caracterização dos eletrodos modificados}

As análises de superfície foram feitas em pastilhas cilíndricas de grafite com $3 \times 6,38 \mathrm{~mm}$.

O microscópio foi acoplado a um detector EDX modelo 7060 (resolução $133 \mathrm{eV}$ ). A análise foi feita com um feixe de elétrons de 20,00 KV de potência, uma distância de trabalho (WD) de $25 \mathrm{~mm}$; um detector SE1 (detector de elétrons secundários) permitiu um aumento de 3.000 e/ou 7.000 vezes para caracterizar a morfologia das amostras.

A geração de hidrogênio de uma solução de $\mathrm{H}_{2} \mathrm{SO}_{4}$ também foi usada para caracterizar o filme poli (ácido éter alílico $p$ benzenossulfônico) contendo partículas metálicas dispersas. Para este propósito, os EMs foram conectados a uma cela eletrolítica convencional contendo $0,1 \mathrm{~mol} \mathrm{~L}^{-1} \mathrm{de}_{2} \mathrm{SO}_{4}$ e varreduras de potencial foram feitas entre 0 a $-1,0 \mathrm{~V}$ versus $\mathrm{Ag} / \mathrm{AgCl}$ a $10 \mathrm{mV} \mathrm{s}^{-1}$. Vários experimentos foram realizados com o propósito de estudar a estabilidade destes eletrodos.

\section{Hidrogenação eletrocatalítica dos substratos orgânicos usando SEM}

1,6 moles $\left(0,02 \mathrm{~mol} \mathrm{~L}^{-1}\right)$ de benzaldeído, $n$-valeraldeído, eugenol, isoeugenol, fenilacetileno, 3-butin-1-ol, 2-ciclo-hexanona, isoforona, acetofenona e benzofenona como substratos foram adicionados a $80 \mathrm{~mL}$ de uma solução de $\mathrm{H}_{2} \mathrm{SO}_{4} 0,1 \mathrm{~mol} \mathrm{~L}^{-1}$ numa cela eletrolítica convencional. Para os substratos imiscíveis, tercbutanol foi utilizado como co-solvente na proporção de 3:7 para a solução ácida. Os EMs foram polarizados a um potencial constante de $-0,7 \mathrm{~V}$ versus $\mathrm{Ag} / \mathrm{AgCl}$ sob forte agitação magnética durante 24 h. Desprendimento de hidrogênio no eletrodo de trabalho pôde ser observado. Os produtos foram extraídos com $\mathrm{CH}_{2} \mathrm{Cl}_{2}$, a solução foi seca e evaporada. O resíduo foi analisado por métodos convencionais como c.g.l., FTIR e ${ }^{1} \mathrm{H}$ RMN e os produtos identificados por comparação com amostras originais.

\section{Caracterização por ${ }^{1} \mathrm{H}$ RMN e FTIR dos produtos da hidrogenação exaustiva da acetofenona e da benzofenona com EM Ni/Pd}

Ciclo-hexil-metil-carbinol: ${ }^{1} \mathrm{H}$ RMN $\delta(\mathrm{ppm}): 1,1\left(\mathrm{~m} 10 \mathrm{H} \mathrm{CH}_{2}\right.$ ciclo-hexano alifático), 1,8 (m, $\mathrm{CH}$ anel), 3,4 (dd, 3H, $J=14,1 \mathrm{~Hz}$ and $\left.J=7,0 \mathrm{~Hz}, \mathrm{CH}_{3}\right), 3,9(\mathrm{~m}, \mathrm{CH}-\mathrm{OH})$ e 4,7

( -OH largo). FTIR (KBr): v $\left(\mathrm{cm}^{-1}\right) 3365(\mathrm{OH})$ e $2974(\mathrm{CH}$ alifático saturado).

Diciclo-hexil-carbinol: ${ }^{1} \mathrm{H} \mathrm{RMN} \delta$ (ppm): 1,1-1,4 (m, 20H ciclohexano alifático), 1,7 e 1,8 (m, 2x CH de anel) e 4,1 (q, J=7,1 Hz, HC-OH). FTIR (KBr): v ( $\left.\mathrm{cm}^{-1}\right): 3373(\mathrm{OH})$ e 2933 (CH alifático saturado).

\section{RESULTADOS E DISCUSSÃO}

A preparação dos EMs por recobrimento de bastões de grafite com o poli (ác. éter alílico p-benzenossulfônico) já está descrita na literatura. ${ }^{18-24}$ Resulta da eletrooxidação do monômero e produz um filme estável quimica e fisicamente que pode ser reutilizado nas experiências de hidrogenação eletrocatalítica. $O$ polímero pode também ser removido do eletrodo por polimento e o bastão de grafite pode ser usado repetidamente.

A caracterização do filme polimérico por microscopia eletrônica de varredura (MEV) ${ }^{28}$ (Figura 1) mostrou que é composto por oxigênio $(12,96 \%)$, carbono $(86,6 \%)$ e enxofre $(0,44 \%)$, proporções estas que correspondem à composição do monômero. As correspondentes micrografias mostram um revestimento homogêneo.
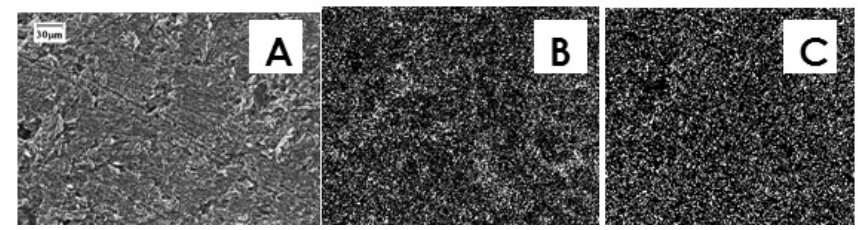

Figura 1. (A) Micrografia de superfície, (B) mapeamento para o oxigênio e (C) mapeamento para o enxofre presentes no filme poli (éter alílico do ác. p-benzenossulfônico)

O eletrodo revestido foi imerso por $2 \mathrm{~h}$ numa solução de íons de níquel para ocorrer a troca iônica dos prótons do filme com os íons metálicos da solução. A subseqüente eletrorredução foi feita por varreduras catódicas repetidas, até não ser mais observada corrente. A incorporação de partículas de níquel incorporadas na matriz polimérica foi confirmada por MEV mostrando 8,29\% de partículas dispersas de forma irregular (Figura 2).

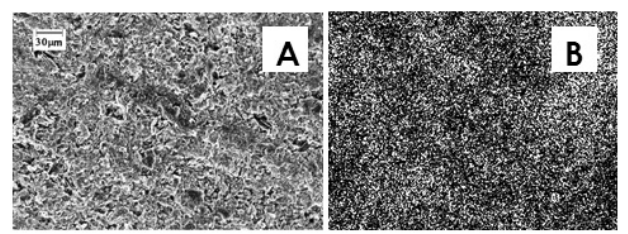

Figura 2. (A) Micrografia de superfície e composição elementar do níquel (B) no filme poli (éter alílico do ác. p-benzenossulfônico)

Como foi previamente descrito, ${ }^{18-24}$ o agora chamado EM/Ni apresenta melhor atividade eletrocatalítica para a evolução de hidrogênio que o filme sem as partículas de níquel. Por outro lado, níquel é apropriado para a ocorrência de uma reação de deslocamento ${ }^{18,20,25,26}$ quando mergulhado numa solução de um sal de metal mais nobre, como $\mathrm{PdCl}_{4}$ e $\mathrm{PtCl}_{4}$ em meio ácido. Assim, o EM/Ni foi mergulhado por $5 \mathrm{~h}$ nas respectivas soluções de íons paládio e platina para produzir os respectivos EM/Pd e EM/Pt.

A caracterização por MEV destes novos EMs (Figura 3) revelou uma deposição heterogênea de paládio, muito parecida com clusters (2,59\% Pd e 0,17\% Ni). A incorporação de platina mostrou-se menos efetiva, dificilmente distinguível por análise de MEV, mostrada na Figura 4, contendo 1,23\% Ni e 0,40\% Pt. Não obstante, a pequena quantidade de platina incorporada responde por um aumento na atividade eletrocatalítica do eletrodo frente à redução de prótons e desprendimento de hidrogênio quando comparado com o EM Ni (Figura 5), o que confirma um comportamento interessante deste eletrodo. Os testes de desprendimento de hidrogênio feitos com o mesmo eletrodo por diversas vezes mostraram que os mesmos são estáveis. 


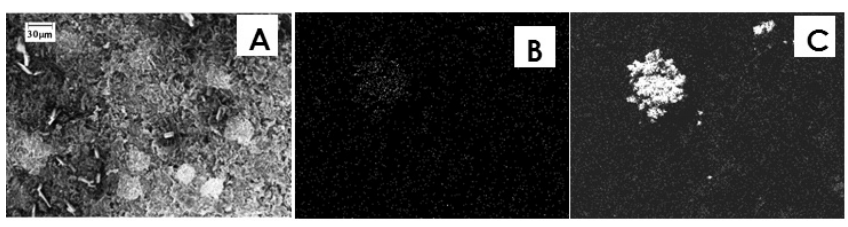

Figura 3. Micrografia de superfície do EM Ni/Pd (A) e composição elementar do níquel (B) e paládio $(C)$ no EM Ni/Pd

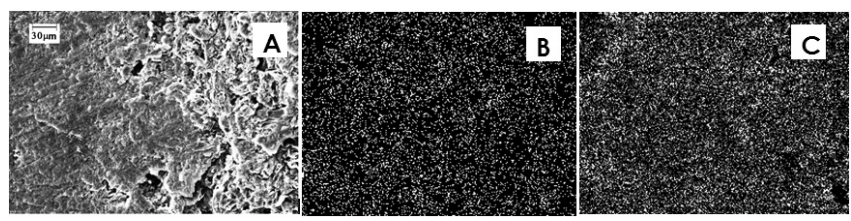

Figura 4. Micrografia de superfície EM Ni/Pt (A) e composição elementar do níquel (B) e platina $(C)$

Os EMs foram testados quanto à sua eficiência na hidrogenação de substratos orgânicos selecionados, que apresentam diversos tipos de insaturações e funções, tais como aldeídos e cetonas alifáticas (saturadas e insaturadas), aromáticos, olefinas, acetilenos saturados e insaturados, e moléculas polifuncionais apresentando um alto grau de substituição com restrições estéricas, fator de obstrução importante para reações que ocorrem em duas fases. A Tabela 1 sumariza os resultados obtidos. Em todos os experimentos foi aplicado um potencial de - 0,7 V versus $\mathrm{Ag} / \mathrm{AgCl}$ para reduzir prótons da solução ácida a hidrogênio radicalar, que adsorve na superfície metálica das partículas no filme. Parte dos prótons transforma-se em hidrogênio molecular ${ }^{17}$ e parte reage com as moléculas orgânicas igualmente adsorvidas pelas suas insaturações, hidrogenando-as. A análise qualitativa e quantitativa dos produtos foi executada por cromatografia a gás, comparando com amostras puras e/ou analisados por métodos convencionais como ${ }^{1} \mathrm{H}$ RMN ou FTIR.

De acordo com os dados apresentados na Figura 5 (maior corrente de geração de hidrogênio), os melhores resultados foram obtidos com o EM Ni/Pd, que se revelou ativo para a maior parte dos substratos orgânicos, produzindo rendimentos de razoável a bom. Há de notar

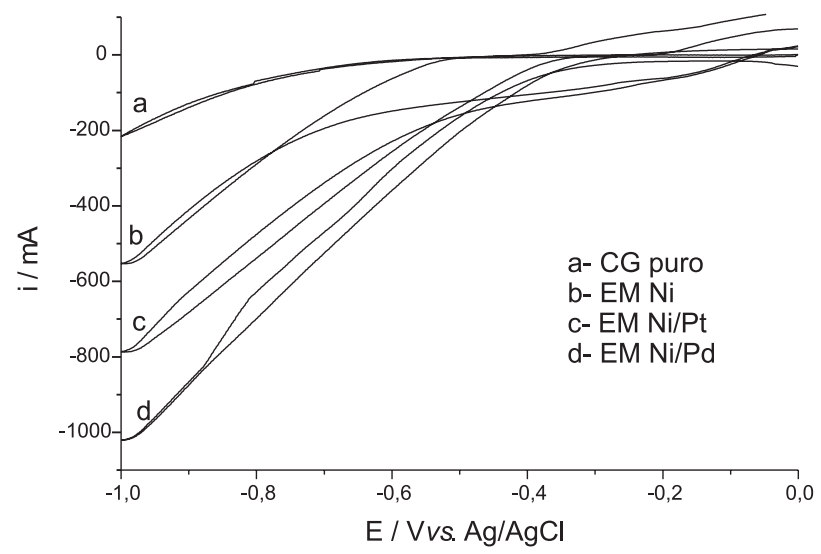

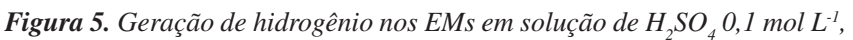
velocidade de varredura $10 \mathrm{mVs}^{-1}$

que os EMs não foram capazes de hidrogenar substratos orgânicos muito volumosos, como o $n$-valeraldeído, devido à sua cadeia molecular hidrofóbica que adquire uma forma esférica no meio aquoso, e isoforona que possui três grupos metilas ligados ao anel onde estão as insaturações. A importância do paládio em promover adsorções eficientes de substratos orgânicos é evidenciada pelos resultados obtidos para os substratos polifuncionais eugenol e isoeugenol, moléculas volumosas com extensas insaturações conjugadas envolvendo a dupla ligação ou o par de elétrons com o anel aromático. Foi verificada a hidrogenação seletiva da dupla ligação.

Fenilacetileno e 3-butin-1-ol tiveram as suas triplas ligações hidrogenadas e benzaldeído e ciclo-hexanona deram álcool benzílico e ciclo-hexanol, respectivamente.

2-ciclo-hexen-1-ona deu dois possíveis produtos: a hidrogenação da dupla, obtendo-se ciclo-hexanona com os três EMs e, a hidrogenação total, dando ciclo-hexanol com os EMs Ni/Pd e Ni/Pt. Assim, é de se notar a seletividade obtida usando o EM/Ni que hidrogenou apenas a dupla ligação.

Particularmente interessantes foram os resultados obtidos com as cetonas aromáticas: acetofenona e benzofenona foram totalmente hidrogenadas dando ciclo-hexil-metil-carbinol e diciclo-hexil-

Tabela 1. Hidrogenação eletrocatalítica dos substratos utilizando os EMs a - 0,7 V vs. $\mathrm{AgCl}$ por $24 \mathrm{~h}$ em solução de $\mathrm{H}_{2} \mathrm{SO}_{4} 0,1$ mol L $\mathrm{L}^{-1} \mathrm{e}$ terc-butanol $(3: 7 \mathrm{~V} / \mathrm{V})$

\begin{tabular}{|c|c|c|c|c|}
\hline Substrato & Produto & EM Ni & $\mathrm{EM} \mathrm{Ni/Pd}$ & $\mathrm{EM} \mathrm{Ni} / \mathrm{Pt}$ \\
\hline Benzaldeído & Álcool benzílico & $93,1 \%$ & $96,0 \%$ & $90,6 \%$ \\
\hline n-valeraldeído & - & Não reativo & Não reativo & Não reativo \\
\hline Eugenol & 2-metoxi-4- $n$-propil-fenol & -1 & $50,0 \%$ & Não reativo \\
\hline Isoeugenol & 2-metoxi-4- $n$-propil-fenol & -1 & $33,0 \%$ & Não reativo \\
\hline Fenilacetileno & Etil benzeno & $75,5 \%$ & $7, .6 \%$ & -1 \\
\hline 3-butin-1-ol & $n$-butanol & Não reativo & $68,1 \%$ & $30,1 \%$ \\
\hline 2-ciclo-hexen-1-ona & $\begin{array}{l}\text { Ciclo-hexanona } \\
\text { Ciclo-hexanol }\end{array}$ & $49,6 \%$ & $\begin{array}{l}48,0 \% \\
40,0 \%\end{array}$ & $\begin{array}{l}58,7 \% \\
15,6 \%\end{array}$ \\
\hline Ciclo-hexanona & Ciclo-hexanol & $22,7 \%$ & $71,5 \%$ & $47,0 \%$ \\
\hline Isoforona & - & Não reativo & Não reativo & Não reativo \\
\hline Acetofenona & $\begin{array}{c}\text { Ciclo-hexil-metil-carbinol } \\
\text { Metilfenilcarbinol }\end{array}$ & $\begin{array}{c}-1 \\
80,2 \%\end{array}$ & $65,2 \%$ & $\begin{array}{l}-1 \\
-1\end{array}$ \\
\hline Benzofenona & Diciclo-hexil-carbinol & -1 & $53,4 \%$ & -1 \\
\hline
\end{tabular}

${ }^{1}$ Este substrato não foi submetido à hidrogenação eletrocatalítica com este eletrodo. 
carbinol quando se usou EM Ni/Pd, enquanto que o EM Ni revelou atividade somente para a hidrogenação da carbonila na acetofenona. Esta seletividade alcançada com diferentes EMs é muito importante para a hidrogenação de compostos aromáticos e nunca foi antes reportada na literatura para hidrogenações eletrocatalíticas. No caso do benzaldeído e do fenilacetileno, substratos igualmente aromáticos, os anéis benzênicos não foram hidrogenados devido a grupos funcionais (aldeído e acetileno) muito reativos que se hidrogenam muito facilmente e se dessorvem rapidamente, após a redução da carbonila ou da tripla ligação, respectivamente. As cetonas aromáticas são menos reativas e toda a extensão molecular conjugada fica fortemente adsorvida no eletrodo contendo paládio, o que permite a hidrogenação do anel. O papel chave do paládio na etapa da adsorção se evidencia quando se comparam os EM Ni e EM $\mathrm{Ni} / \mathrm{Pd}$, quando este último promove a hidrogenação da carbonila e da tripla ligação na acetofenona e no 3-butin-1-ol, respectivamente, para dar o álcool secundário e o radical etila.

\section{CONCLUSÃO}

Novos eletrodos modificados contendo partículas de paládio e platina dispersas no filme poli (éter alílico do ác. $p$-benzenossulfônico) foram preparados a partir da incorporação de partículas de níquel por troca iônica e da subsequiente troca e deposição dos metais nobres por reações de deslocamento galvânico. As análises por MEV destes novos eletrodos modificados (EMs) revelaram uma deposição eficiente de paládio, mas pouca deposição de platina. O comportamento destes EMs quanto à redução de prótons de uma solução ácida apontou para a potencialidade de seu uso nas hidrogenações eletrocatalíticas de substratos orgânicos.

Eletrólise a potencial constante favorável para a formação de hidrogênio atômico, mas distante da região onde se observa desprendimento de hidrogênio molecular, permitiu a estes eletrodos $(\mathrm{Ni}, \mathrm{Ni} / \mathrm{Pt}$ e Ni/Pd) hidrogenar um grande número de substratos orgânicos estrategicamente escolhidos de acordo com suas peculiaridades estruturais. Uma comparação da reatividade entre os vários metais foi possível. Para a grande maioria deles, o EM Ni/Pd mostrou ser o mais eficiente. Substratos volumosos e com altos graus de insaturações só puderam ser hidrogenados com o EM Ni/Pd. Os dados da hidrogenação permitiram correlacionar a extensão da conjugação com a eficiência da adsorção da molécula na superfície do eletrodo. Cetonas aromáticas foram totalmente hidrogenadas a alcoóis alifáticos insaturados, o que é um resultado relevante, pois a hidrogenação convencional de anéis benzênicos com gás hidrogênio e um catalisador requer condições muito mais drásticas com altas temperaturas e pressão.

\section{AGRADECIMENTOS}

Ao apoio financeiro da CAPES e ao Convênio CAPES/GRICES 067/01.

\section{REFERÊNCIAS}

1. Fokin, S.; Z. Elektrochem. 1960, 12, 749.

2. Mcgrath, M. P.; Sall, E. D.; Tremont, S. J.; Chem. Rev. 1995, 95, 381.

3. Johnstone, R. A. W.; Wilby, A. H.; Entwistle, I. D.; Chem. Rev. 1985, 85, 129.

4. Hoelscher, H. E.; Poynter, W. G.; Weger, E.; Chem. Rev. 1954, 54, 575 .

5. Brieger, G.; Nestrick, T. J.; Chem. Rev. 1974, 74, 567.

6. House, H. O.; Modern Synthetic Reactions, $2^{\text {nd }}$ ed., W. A. Benjamin: Menlo Park, 1979, 1.

7. Ruest, L. ; Ménard, R. ; Moreau, V. ; Laplante, F.; Can. J. Chem. 2002, $80,1662$.

8. Bockris, J. O'M. Em Comprehensive treatise of electrochemistry; Bockris, J. O’M.E.; Yeager, R. E., eds.; Plenum Press, New York 1981, vol. 3 , chap. 1 .

9. Lasia, A. Em Handbook of fuel cells: Fundamentals, technology and applications; Vielstich, W.; Lamm, A.; H.A. Gasteiger, H. A., eds.; John Wiley and Sons Ltd.: New York, 2003, vol. 2, p. 416.

10. Chagnes, A.; Laplante, F.; Kerdouss, F.; Proulx, P.; Ménard, H.; Can. J. Chem. 2004, 82, 641 .

11. Haber, F.; Phisik. Chem. 1900, 32, 193.

12. Pereira, A. C.; Santos, A. S.; Kubota, L. T.; Quim. Nova 2002, 25, 1012.

13. Moutet, J-C.; Org. Prep. Proced. Int. 1993, 24, 309; Moutet, J-C.; Actual. Chimique 1998, 63.

14. Coche, L.; Moutet J. -C.; J. Am. Chem. Soc. 1987, 109, 6887.

15. Ono, S.; Hayashi, T.; Bull. Chem. Soc. Jpn. 1953, 26, 11.

16. Junghans, K.; Chem. Ber. 1974, 107, 3191.

17. Lofrano, R. C. Z.; Queiroz, J. V.; Romero, J. R.; J. Mol. Catal. A 2001, 174, 231.

18. Pontólio, J. O. S.; Purgato, F. L. S.; Romero, J. R.; Quim. Nova 2004, 27,550 .

19. Lofrano, R. C. Z.; Madurro, J. M.; Abrantes, L. M.; Romero, J. R.; J. Mol. Catal. A: Chem. 2004, 218, 73.

20. Fundo, A. M.; Costa, M. I. C. F.; Romero, J. R.; Abrantes, L. M.; Ciência e Tecnologia dos Materiais 2005, 17, 12.

21. Costa, M. I. C. F.; Fundo, A. M.; Abrantes, L. M.; Romero, J. R.; J. Appl. Electrochem. 2006, 36, 43.

22. Steter, J. R.; Pontólio, J. O.; Campos, M. L. A. M.; Romero, J. R.; J. Braz. Chem. Soc. 2008, 19, 660.

23. Fundo, A. M.; Purgato, F. L. S.; Romero, J. R.; Abrantes, L. M.; J. Appl. Electrochem. 2008, 38, 861 .

24. Tenreiro, A. M.; Nabais, C.; Correia, J. P.; Fernandes, F. M. S. S.; Romero, J. R.; Abrantes, L. M.; J. Solid State Electrochem. 2007, 11, 1059.

25. Kokkidinis, G.; Papoutsis, A.; Stoychev, D.; Milchev, A.; J. Electroanal. Chem. 2000, 48, 486.

26. Liu, S.; Li, J-R.; Jiang, L.; Colloids Surf., A 2005, 57, 257.

27. Alfa graphite sticks 6.15 x $51 \mathrm{~mm}$. pure $99.9995 \%$.

28. Kestenbach, H.-J.; Filho, W. J. B.; Microscopia Eletrônica: Transmissão e Varredura, ABM: São Paulo, 1994. 